\title{
Clinical response in osteogenic sarcoma patients treated with ultra-dilute medicines
}

\author{
Prasanta Banerji*, and Pratip Banerji \\ PBH Research Foundation, 10/3/1 Elgin Road, Kolkata-700020, west Bengal, India
}

\begin{abstract}
Osteogenic sarcoma management is a challenge for the cancer community globally. Not much awareness or information about the use of complementary and alternative medicine (CAM), more specifically treatment with ultra-dilute medicines, is available for such cases. Our experience in this will show that treatment of this dreaded disease with ultra-dilute medicines can be considered as a possible option.

This treatment has been well tested in the clinical setting, by virtue of it being in use for decades with a good degree of success. This has inspired us to follow closely data available at our institution clinics where we treat this disease by using the "Banerji Protocols". These protocols consist of the use of disease specific ultra-dilute medicines in specific dilutions, in pre-set dosage patterns. By this conservative treatment, surgical interventions such as amputation of affected parts can be avoided and the patient returned to health.

Recent experimental studies of "Banerji Protocol" medicines used in cancer treatment have revealed that these medicines act both at the molecular as well as the genetic levels resulting in growth arrest and apoptosis in tumor cells. The findings suggest that such tumor cell specific cytostatic and cytotoxic effects could be responsible for the observed therapeutic efficacy of these medicines in cancer treatment.
\end{abstract}

\section{Introduction}

Osteosarcoma is the most common malignant bone tumor in youth. The average age at diagnosis is 15 . Boys and girls have a similar incidence of this tumor until late adolescence, at which time boys are more commonly affected. The cause is not known. In some cases, osteosarcoma runs in families and at least one gene has been linked to increased risk. This gene is also associated with familial retinoblastoma, a cancer of the eye which occurs in children. It appears to be a defective tumor inhibitor gene. This disease is an aggressive neoplasm arising from primitive transformed cells of mesenchymal origin that exhibit osteoblastic differentiation and produce malignant osteoid. It is the most common histological form of primary bone cancer. They comprise of a diverse group of primary and metastatic neoplasms in both children and adults. The most common small cell tumors of bone include Ewing sarcoma/primitive neuroectodermal tumor, small cell osteosarcoma. It is the eighth most common form of childhood cancer, comprising $2.4 \%$ of all malignancies in pediatric patients and approximately $20 \%$ of all bone cancers [1-3]. It is more common in males than in females [4], and often seen in teenage boys who are taller than average [5]. Primary bone cancer is rarely diagnosed in children before the age of five or adults over the age of sixty. Incidence of Osteogenic Sarcoma increases with age until a peak in late childhood or adolescence around the time of puberty, after which incidence declines [6-8]. A second less pronounced peak is observed in older adults above the age of 65 years (Ottaviani and Jaffe, 2010) [9].

The tumor may be localized at the end of the long bones. Most often it affects the upper end of tibia (19\%) or humerus (10\%) or lower end of femur (42\%). Osteogenic Sarcoma tends to affect regions around the knee in $60 \%$ of cases, $15 \%$ around the hip, $10 \%$ at the shoulder and $8 \%$ in the jaw. Radiological examination reveals that the tumor is solid, hard, irregular ("fir-tree," "moth-eaten" or "sun-burst" appearance in $\mathrm{X}$-ray plates) due to the presence of tumor spicules of calcified bone radiating from the surface of the tumor $[10,11]$.

The characteristic feature of Osteogenic Sarcoma is presence of bone formation within the tumor with or without central calcification. Tumor cells are very pleomorphic; some exhibit multinucleated osteoclast-like giant cells with atypical mitoses. Tumor cells may resemble bone cells, cartilage cells or fibroblast cells. Osteogenic Sarcoma is one of the few tumors that remains localized to the site of origin, though sometimes metastasizes to other sites, usually to the lungs or other bones. The tumor can recur in the same place, or at distant sites like lungs or other bones. Patients suffering from Osteogenic Sarcoma show pain on weight bearing portions. About $53 \%$ patients present minor trauma followed by swelling around the site of symptom $[12,13]$.

The traditional treatment of Osteogenic Sarcoma is the application of antitumor agent along with radiation or surgery. Antitumor effects of bisphosphonates such as zoledronic acid (ZOL) or combined effects of ZOL with other anticancer agents against Osteogenic Sarcoma cells

Correspondence to: Dr. Prasanta Banerji, PBH Research Foundation, 10/3/1 Elgin Road, Kolkata-700020, India, Tel: + 9133 30582818; Fax: + 9133 22877275; Email: info@pbhrfindia.org; prasantabanerji@gmail.com

Dr. Pratip Banerji, PBH Research Foundation, 10/3/1 Elgin Road, Kolkata-700020, India, Tel: + 9133 30582818; Fax: + 9133 22877275; E-mail: info@pbhrfindia.org; pratipbanerji@gmail.com

Key words: osteosarcoma; osteogenic sarcoma; ultra-dilute medicine; banerji protocols; symphytum officinalis; calcarea phosphoricas

Received: December 14, 2016; Accepted: January 10, 2017; Published: January 14, 2017 
have been reported. Combined therapy (low-concentration ZOL and low-dose radiation) has been reported to yield significant growth inhibitory effects [14]. Limb-salvage treatment and amputation have been proved to be a satisfactory measure against Osteogenic Sarcoma [15]. Surgical removal of the malignant tumors from the proximal femur also proved to be satisfactory [11]. Different plant products also showed antitumor results on Osteogenic Sarcoma cells [16-20]. Even though, as mentioned above, there are many interventions possible, the prognosis leaves much to be desired, both in terms of survival as well as Quality of Life (QoL).

We present here case reports and clinical responses of two Osteogenic Sarcoma patients treated with a combination ultradilute natural remedy protocol comprising of Symphytum, Calcarea phosphorica and Carcinosin. Such protocols with combination ultradilute natural medicines have been used in our clinic to successfully treat other malignancies [21]. These treatment protocols offer viable and much more affordable alternative to the conventional standard of care than current therapeutic protocols, which in many instances adversely affect the Quality of Life(QoL) of patients due to debilitating consequences of the treatment.

\section{Case studies}

\section{Case 1}

In the first case the patient, an 8-year-old male boy visited the clinic with swelling of left knee and difficulty in knee flexion. He was suffering for 5 to 6 months. The initial radiological report of X-ray of left knee dated 27.04.2003 was, "A large bony cyst with osteolytic lesion in metaphysis with sclerosis at edges of lower end of left femur". The case was confirmed as Osteogenic Sarcoma and the parents of the child were advised to amputate the leg from above the tumor. Repeat of the X-ray dated 05.06.2003 (Figure 1A) showed, "Well defined eccentric lesion in metaphysis with sclerosis at edges of lower end of left femur".

The observation during treatment from the X-ray of left knee

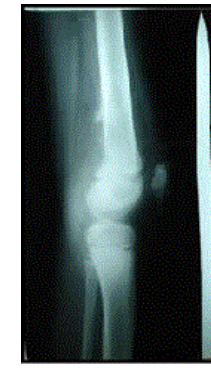

A

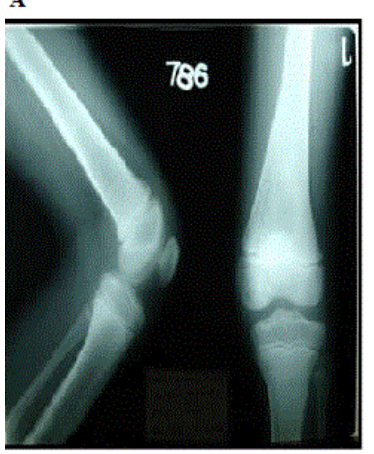

C

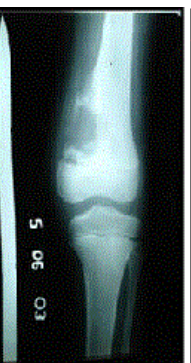

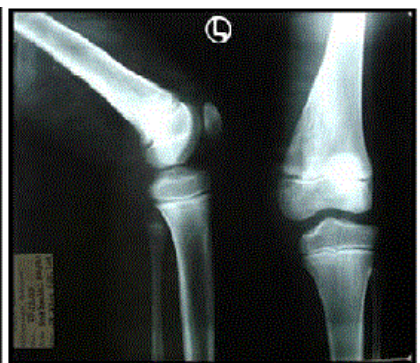

B

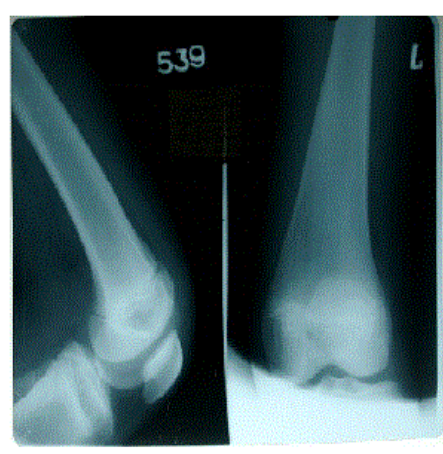

D

Figure 1. Four successive $X$ - ray reports of the knee. Adated 05.06.2003, B dated16.12.2003, $\mathrm{C}$ dated 14.08.2004 and D dated 25.08.2008. dated 16.12.2003 (Figure 1B) was, "large osteolytic reaction noted in metaphysis of left femur with periosteal reaction".

The histopathology (Site of biopsy-lower end of femur) report dated 12.06.2003 (Figure 2) showed, "Poorly differentiated sarcomatous lesion".

The patient was treated with the remedies Symphytum 200c two doses a day, Calcarea Phosphorica $3 \mathrm{X}$ two doses a day and Carcinosin $30 \mathrm{c}$ one dose every alternate day. The treatment was continued for one year and four months. The swelling gradually subsided and now the architecture of the knee has completely returned to normal.

An X-ray dated 14.08.2004 (Figure 1C) shows, "Comparative study with that of previous skiagram dated 16.12.2003 reveals remineralization seen at the lower 3rd of left femur"

After $3 \frac{1}{2}$ years without any medication follow up X-ray was done on 25.08.2008 (Figure 1D) and this showed "Comparative study with that of previous skiagram dated $14^{\text {th }}$ August, 2004 shows the appearance of the lower $3^{\text {rd }}$ of left femur is almost normal"

He had no complications during treatment.

The patient is now symptom free and leading a trouble-free life.

\section{Case 2}

In the next instance, a female aged 33 years came to us from a remote village in Bangladesh on the 22.07.2005 and presented with pain and swelling in the right shoulder of $1 \frac{1}{2}$ months duration.

An MRI of the right shoulder done on the 06.07.2005 (Figure 3A) showed "A large expansile osteolytic mass is seen in metaphysis and part of greater tuberosity of right humerus. There is extension to the paraosteal soft tissue".

An X-ray of the right shoulder was done on the 07.07.2005 (Figure 3B) showed, "osteolytic lesion in the upper part of the right humerus".

A radio-isotope bone scan had been done on 26.07.2005 (Figure 3C) and showed, "Increased uptake at right shoulder is compatible with increased osteogenic activity in the region. Rest of the skeletal tissue image morphology is within normal limits".

C.T. guided F.N.A.C of the lytic lesion in the humerus done on 28.06.2005 (Figure 4) showed, "the overall cytomorphological features are of malignant tumour of mesenchymal origin. The possibility of soft tissue sarcoma like synovial sarcoma with secondary involvement of the bone has been favored".

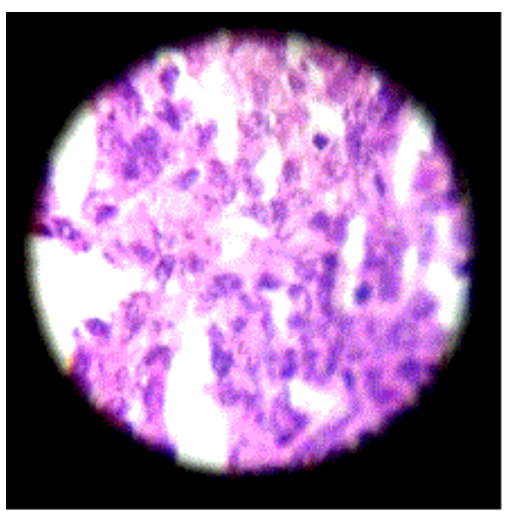

Figure 2. Histopathology of the lower femur. 

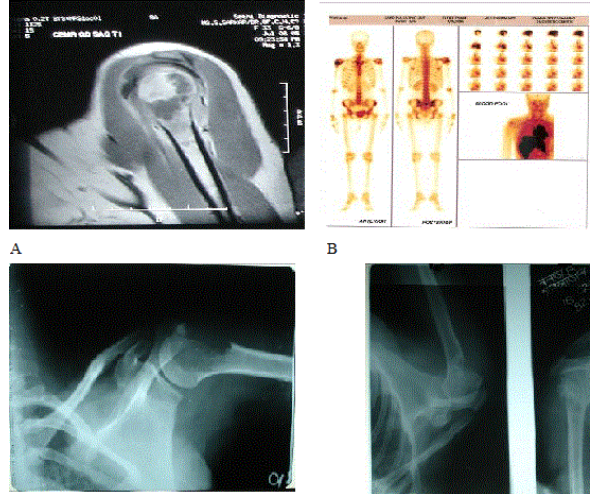

D
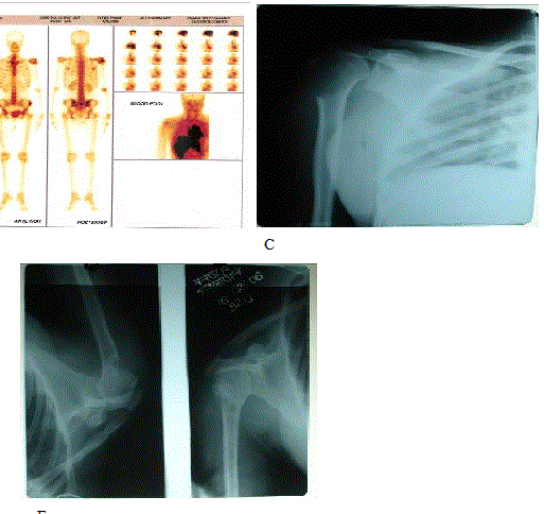

Figure 3. One MRI of the right shoulder A dated 06.07.2005, one bone scan B dated 26.07.2005 and three successive $\mathrm{X}$ - ray reports of the right shoulder. $\mathrm{C}$ dated 07.07.2005, $\mathrm{D}$ dated 26.07.2005 and $\mathrm{E}$ dated 18.02.2006.

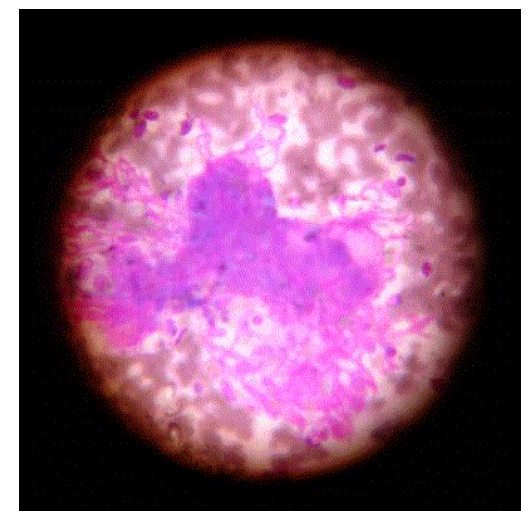

Figure 4. C.T. guided F.N.A.C of the lytic lesion in the humerus.

Review report of the same slide on 04.07.2005 (Figure 3D) by Chittaranjan National Cancer Institute, was reported as, "Impression: The features are of malignant mesenchymal tumour-Pleomorphic sarcoma possibility of primary bone tumor is to be considered".

After undergoing treatment from us with the medicines Symphytum 200c two doses a day, Calcarea Phosphorica 3X two doses a day and Carcinosin 30c, one dose every alternate day, patient felt much better and the swelling and pain in right shoulder area subsided within 6-7 months.

An X-ray right shoulder done on 18.02.2006 (Figure 3E) showed, "Much improvement is seen of the osteolytic lesion in the upper part of the right humerus".

\section{Discussion}

The traditional treatment for Osteogenic Sarcoma is the surgical amputation of the concerned body parts $[10,15]$ or use of chemotherapeutic regimens [14,17,22-24]. The current report describes remarkable cases of positive clinical response achieved in Osteogenic Sarcoma patients treated with combination ultra-dilute medicines used in our clinics in different combinations and therapeutic regimens to successfully treat various malignant tumors. Different cases and cancer-types, submitted by us to the National Cancer Institute (NCI) have formerly been validated by the NCI Best Case Series Program (BCS).

In advanced countries, most alternative health care professionals

use ultra-dilute medicines in combination with other approaches (nutritional and immune system support, diet, and detoxification programs, etc.), so it's not typically considered the primary or stand-alone therapy for cancer. However, in our experience these medicines, when administered in different combinatorial regimens in a personalized manner depending on the clinical and pathological parameters of individual patients offer extremely effective therapeutic options for treatment of human malignancies. Such treatment protocols have been successfully used in treating a large number of patients with different cancers in our clinic over the past few decades. Positive clinical outcome of these treatment protocols was deemed sufficient to warrant initiation of prospective research follow up by the Office of Cancer Complementary and Alternative Medicine (OCCAM) of the NCI of the United States [21].

Several ultra-dilute medicines have been used to treat bone deformities and other orthopaedic conditions but Osteogenic Sarcoma has remained a challenge for any and every system of medicine. With a view to exploring the therapeutic efficacy of combination of these ultra-dilute natural remedies for the treatment of Osteogenic Sarcoma, we have undertaken clinical trials of various treatment protocols developed in our clinic with these medicines. This study reports the success of healing of Osteogenic Sarcoma by a treatment regimen consisting of combination of three ultra-dilute natural remedies for reasons discussed below.

Symphytum officinale or just "Symphytum" is prepared from the root of the common herb "comfrey" which stimulates the growth of epithelium on ulcerated surfaces. It generally acts on joints and is of great use in wounds penetrating to perineum and bones and for the neuralgia of knee. It is mainly used for the healing of broken bones.

Calcarea phosphorica is calcium phosphate a mineral ingested mostly for disorders associated with nutritional deficiency supplementing and in the mineralization of teeth and bones.

Carcinosin is prepared from breast cancer tissue. It is mainly used for Chronic fatigue syndrome (CFS) - weakness and exhaustion, associated with tenderness in the muscles. This is often accompanied by dizziness, numbness, nausea, insomnia, asthma, bronchitis, abdominal pain associated with constipation etc. Carcinosin may be prescribed for those who have a personal or family history of cancer.

The molecular mechanism for the eradication of the tumor by these three remedies needs further investigation. It would be interesting to investigate if these remedies activate the pathway involving Syndecan-2, reported to be significantly under expressed in Osteosarcoma cells, which is the main causative agent of beta-catenin signaling inducing apoptosis in these malignant cells [25]. Our papers earlier published in vitro investigations with different combination ultra-dilute medicine regimens effective in treating brain cancer [26] and breast cancer [27] revealed preferential induction of cell death due to telomere erosion and activation of cell death response pathways in brain cancer and breast cancer cells respectively. Similar in-depth experimental studies with the three combination remedies described in this report will also help unravel the underlying molecular mechanisms responsible for their therapeutic efficacy.

\section{References}

1. Hameed M (2007) Small round cell tumors of bone. Arch Pathol Lab Med 131: 192204.[Crossref]

2. Selvarajah S, Yoshimoto M, Ludkovski O, Park PC, Bayani J, et al. (2008) Genomic signatures of chromosomal instability and osteosarcoma progression detected by 
high resolution array CGH and interphase FISH. Cytogenet Genome Res 122: 5-15. [Crossref]

3. Li S, Siegal GP (2010) Small cell tumors of bone. Adv Anat Pathol 17: 1-11.[Crossref]

4. Smith PG (1992) In: Cancer Incidence in Five Continents. Comparison between registries: age-standardized rates. Parkin DM, Muir CS, Whelan SL, Gao YT, Ferlay J (Eds) France: IARC Scientific Publications.

5. Worch J, Matthay KK, Neuhaus J, Goldsby R, DuBois SG (2010) Osteosarcoma in children 5 years of age or younger at initial diagnosis. Pediatr Blood Cancer 55: 285289. [Crossref]

6. Arndt V, Lacour B, Steliarova-Foucher E, Spix C, Znaor A, et al. (2007) Up-todate monitoring of childhood cancer long-term survival in Europe: tumours of the sympathetic nervous system, retinoblastoma, renal and bone tumours, and soft tissue sarcomas. Ann Oncol 18: 1722-1733.

7. Magnanti BL, Dorak MT, Parker L, Craft AW, James PW, et al. (2008) Sex-specific incidence and temporal trends in solid tumours in young people from Northern England, 1968-2005. BMC Cancer 8: 89.[Crossref]

8. Eyre R, Feltbower RG, Mubwandarikwa E, Jenkinson HC, Parkes S, et al. (2009) Incidence and survival of childhood bone cancer in northern England and the West Midlands, 1981-2002. Br J Cancer 100: 188-193.[Crossref]

9. Ottaviani G, Jaffe N (2009) The epidemiology of osteosarcoma. Cancer Treat Res 152 3-13.[Crossref]

10. Ruggieri $\mathrm{P}$, Calabrò T, Montalti M, Mercuri M (2010) The role of surgery and adjuvants to survival in Pagetic osteosarcoma. Clin Orthop Relat Res 468: 2962-2968.[Crossref]

11. Wang J, Yin J, Zou C, Xie X, Huang G, et al. (2010) [Surgical treatment of proximal femoral malignant tumors]. ZhongguoXiu Fu Chong Jian Wai KeZaZhi 24: 881-884. [Crossref]

12. Yang JY, Cheng FW, Wong KC, Lee V, Leung WK, et al. (2009) Initial presentation and management of osteosarcoma, and its impact on disease outcome. Hong Kong Med J 15: 434-439.[Crossref]

13. Pan KL, Chan WH, Chia YY (2010) Initial symptoms and delayed diagnosis of osteosarcoma around the knee joint. J OrthopSurg (Hong Kong) 18: 55-57.[Crossref]

14. Ryu K, Murata H, Koto K, Horie N, Matsui T, et al. (2010) Combined effects of bisphosphonate and radiation on osteosarcoma cells. Anticancer Res 30: 2713-2720. [Crossref]

15. Ayerza MA, Farfalli GL, Aponte-Tinao L, Muscolo DL (2010) Does increased rate of limb-sparing surgery affect survival in osteosarcoma? Clin Orthop Relat Res 468: 2854-2859.[Crossref]

16. Yang XJ, Wong MS, Wang NL, Chan SC, Yao XS (2007) Lignans from the stems of Sambucuswilliamsii and their effects on osteoblastic UMR106 cells. J Asian Nat Prod Res 9: 583-591.[Crossref]

17. Jiang MM, Gao H, Dai Y, Zhang X, Wang NL, et al. (2009) Phenylpropanoid and lignan derivatives from Antiaristoxicaria and their effects on proliferation and differentiation of an osteoblast-like cell line. Planta Med 75: 340-345.[Crossref]

18. Mei RQ, Wang YH, Du GH, Liu GM, Zhang L, et al. (2009) Antioxidant Lignans from the Fruits of Broussonetiapapyrifera. J Nat Prod 72: 621-625.[Crossref]

19. Oh SY, Kwon HC, Jeong SH, Joo YT, Lee YJ, et al. (2012) A phase II study of S-1 and oxaliplatin (SOx) combination chemotherapy as a first-line therapy for patients with advanced gastric cancer. Invest New Drugs 30: 350-356.[Crossref]

20. Liu H, Liu JY, Wu X, Zhang JT (2010) Biochemistry, molecular biology, and pharmacology of fatty acid synthase, an emerging therapeutic target and diagnosis/ prognosis marker. Int J Biochem Mol Biol 18: 69-89.

21. Hattinger CM, Pasello M, Ferrari S, Picci P, Serra M (2010) Emerging drugs for highgrade osteosarcoma. Expert OpinEmerg Drugs 15: 615-634.[Crossref]

22. Yang X, Wong M, Wang N, Chan AS, Yao X (2006) A new eudesmane derivative and a new fatty acid ester from Sambucuswilliamsii. Chem Pharm Bull (Tokyo) 54: 676-678. [Crossref]

23. Shao Y, Liu Y, Shao C, Hu J, Li X, et al. (2010) Enhanced tumor suppression in vitro and in vivo by co-expression of survivin-specific siRNA and wild-type p53 protein. Cancer Gene Ther 17: 844-854.[Crossref]

24. Dieudonné FX, Marion A, Haÿ E, Marie PJ, Modrowski D (2010) High Wntsignaling represses the proapoptotic proteoglycan syndecan-2 in osteosarcoma cells. Cancer Res 70: 5399-5408.[Crossref]

25. Banerji P, Campbell DR, Banerji P (2008) Cancer patients treated with the Banerji protocols utilising homoeopathic medicine: a Best Case Series Program of the National Cancer Institute USA. Oncol Rep 20: 69-74.

26. Pathak S, Multani AS, Banerji P, Banerji P (2003)Ruta 6 selectively induces cell death in brain cancer cells but proliferation in normal peripheral blood lymphocytes: A novel treatment for human brain cancer. Int J Oncol 23: 975-982.

27. Frenkel M, Mishra BM, Sen S, Yang P, Pawlus A, et al. (2010) Cytotoxic effects of ultra-diluted remedies on breast cancer cells. Int J Oncol 36: 395-403.[Crossref]

Copyright: (C2017 Banerji P. This is an open-access article distributed under the terms of the Creative Commons Attribution License, which permits unrestricted use, distribution, and reproduction in any medium, provided the original author and source are credited. 